\title{
A Universidade Medieval
}

\author{
Alexandre Correia \\ Professor de Direito Romano na Faculdade \\ de Direito da Universidade de São. Paulo.
}

O esplendor da filosofia escolástica, no século XIII, se explica em parte pela criação e desenvolvimento das grandes universidades de Bolonha, Paris e Oxford.

Instituições do génio cristão medieval e sem qualquer modêlo na antiguidade clássica (1), foram o protótipo das universidades européias, que a seguir se formaram.

Corporações, ao modo da organização social da Idade Média: universitas magistrorum et scolarium, significando o termo universitas o mesmo que, em Direito Romano, universitas personarum (2).

As primeiras universidades medievais resultam de uma formação consuetudinária, ex consuetudine, criações espontâneas das necessidades do meio. Só posteriormente, à medida que as circunstâncias o foram exigindo, receberam estatutos escritos por onde se regessem.

(1) H. Osborn, The Medieval Mind, 409: They had no antique prototypes nothing either in Athen or Rome even ressembled these corporations of masters and students, with their authoritative privileges, their fixed curriculum, and their grades of formally certified attainment. Even the Alexandreia of the Ptolomies, with all the pedantry of its learned litterature and their minute study of the past, has nothing to offer like the scholastic obsequiousness of the medieval University. - Cf. Stephen d'Irsay, Histoire des Universités, I, pág. 29 e segs .

(2) Savigny, Histoire du droit romain au moyen-âge, III, 295 : Le mot universitas a le même sens qu'en droit romain, et il désigne les écoles, non domme corporations. E Savigny remete para o título das Pandectas: quod cuiusque universitatis nomine vel contra eam agatur (III,4). 
Contudo, depois de organizadas as de Bolonha e Paris, modêlo das demais (3), reconheceu-se necessária a autoridade do Papa, do Imperador ou dos reis, para a fundação de um studium generale. Assim, das 81 universidades existentes ao tempo da Reforma, 13 são de formação consuetudinária; 33, fundações dos Papas; 15 , criações dos imperadores ou dos reis; e as 20 restantes, da cooperação dêstes dois últimos (4).

Fautores da alta cultura, os Papas sempre se manifestaram defensores das imunidades e privilégios de mestres e discipulos, contra as usurpações da autoridade eclesiástica, do poder civil ou da burguesia. Assim, Gregório IX, na bula Parens scientiarum de 1231, a Magna Carta da Universidade de Paris, autorizou os magistri a suspender os cursos, em caso de ofensa feita a um professor ou estudante, e não reparada dentro de 15 dias. Honório III, em 1220, foma a defesa dos scolares de Bolonha contra o pod'està, que tentava coarctar as liberdades universitárias. Em 1212 Inocêncio III dá ganho de causa aos mestres da Universidade Parisiense na sua resistência ao Cancellarius, que pretende exigir dêles juramento de obediência.

Por privilégio do Papa, nenhuma autoridade eclesiástica tinha o poder, salvo com autorização especial, de exco-

3. A mais antiga das universidades européias foi a de Salerno, já existente nos princípios do séc. XI; centro de estudos médicos, inspirados nas obras dos árabes. Mas nenhuma influência exerceu na organização da vida universitária ocidental, nem mesmo relativamente à medicina. Cf. Savigny, III, 116 e Schnürer, L Eglise et la Clvilisations au moyeu âge, 541 .

4. S. Tomás admite a competência do poder eclesiástico e do civil para fazerem tais fundações, quando escreve (Contra impugnantes Dei cultum ac Teligionem, Pars II, cap. IX) : ordinare de studio pertinet ad eum qui praeest reipublicae, et praecipue ad auctoritatem apostolicae Sedis, qua universalis Ecclesia gubernatur cui per generale studium providetur. - E Bártolo, o grande romanista, atesta a formação consuetudinária: habere stadium vel licentian docendi procedit ex privilegio tantum vel ex consuetudine longissima. B. in Dig. Vetus, apud Savigny, III, 123 (h). 
mungar um membro da universidade. Sccundando essa imunidade, Filipe Augusto por seu lado, em 1200, isenta os estudantes da alçada do poder civil, colocando-os sob a jurisdição eclesiảstica.

E muitas outras prerrogativas poderiam ser aduzidas. $\mathrm{O}$ desenvolvimento do assunto melhor as evidenciará.

Esste estudo, resumido como necessàriamente há-de ser, limitar-se-á às três grandes típicas universidades medievais : Paris, Bolonha e Oxford.

Deixamos de parte a universidade de Cambridge, de muito menor importância que Oxford, porque só se completou e organizou definitivamente nos fins do século XIV.

1. A Universidade de Paris. - Depois da publicação por Denifle-Chatelain do monumental Chartularium universitatis Parisiensis (4 vols. Paris, 1891-1897), é geralmente considerada a escola catedral de Notre-Dame o berço da Universidade de Paris.

Em 1208 já Inocêncio III se refere à universitas magistrorum. E um diploma universitário de 1221 começa com estas palavras: Nos, Universitas magistrorum et scholarium Parisiensium. E' o apelativo mesmo da universidade medieval, sinónimo de studium generale, studium privilegiatum, studium solemne, école commune, gemeine schul (5).

5. Segundo Savigny, III, 248, é numa decretal de Inocêncio III, do comêço do séc. XIII (G. 7, X, de procur., I 38), com o título Scholaribus Parisiensibus, que pela primeira vez aparece a palavra universitas. Este vocábulo tem, na idade média, as seguintes conexas acepções: a) studium generale ou escola com estudandantes das mais variadas procedências com suas imunidades e privilégios, dando ao diplomado a ius ubique docendi; _ b) asısociação com personalidade moral; — c) corporação de mestres e estudantes, no sentido supra referido; - d) instituto de ensino. funcionando em edifícios próprios; assim dizemos — universidade de Paris (alma mater parisiensis, em 1389), de Bolonha ou de Oxford. 
O corpo professoral, consortium magistrorum, já existente em 1200, dividiu o seu ensino pelas quatro faculdades ou disciplinas: Teologia, Filosofia ou Artes Liberais, Leis. e Medicina (6). Veio por isso, mais tarde, a constituir grupos separados ou faculdades, em sentido semelhante ao da accepção actual dêsse vocábulo, conforme as disciplinas ensinadas.

As diversas faculdades, com existência autónoma e estatutos próprios (outorgados pelo legado do Papa, Cardial Roberto de Courçon, em 1215), foram reconhecidas como tais pela bula de Gregório IX, Parens Scientiarum, de 13 de Abril de 1231. Um diploma universitário as compara aos quatro rios do Paraiso. .

Mas desde 1219 o Papa Honório III proibia o ensino do Direito Civil (romano), por desviar os estudantes do da Teologia que, juntamente com os da arte ou Filosofia, constitui o mais belo florão da universitas magistrorum et scholarium Paristis commorantium (7).

6. Nem tôdas as universidades tinham ou ensinavam tôdas as faculdades; como veremos a seguir, em Bolonha durante muito tempo só se ensinou o direito. Mas não deixava por isso de ser uma universitas.

7. Assim, numa decretal (C. 28, $\mathrm{X}$ de privilegiis, V, 33) citada por Savigny (III, 264, n. a.): ut plenius sacrae paginae instatus, firmiter interdicimus et districtius inhibemus, ne Parisii vel in civitatibus seu aliis locis vicinis quisquam docere vel audire juscivile praesumat. - E Savigny comenta: La decretale s'exprime en termes si généraux, qu'on na saurait la restreindre aux seuls ecclésiastiques.

Em 1180, Gui de Bazoches, estudante do stadium da Cit., descreve entusiàsticamente a intensa vida intelectual que lá so levava: in hac insula perpetuam sibi mansionem pepigere sorores, artes videlicet liberales, et intonante nobilioris eipgnentac thuba decreta leguntar et leges. Hic fons doctrinae salutaris exuberat et, quasi tres rivos ex se limpidissimos ad prata meatium irriganda producens, dividit triplicier intellectum sacre pagine spiritualem in hystoricum allegoricum et moralem. - Chart. Par., I, Introd. 54, apud Irsay, 58. 
População ciosa das suas prerrogativas, buliçosa e inquieta, a gente estudantina se distribui em associações de compatriotas ou nationes, desde 1215-22, com o fim cie auxiliar a administração e a disciplina: Gallicani, Normandi, Picard, Angli. Quatro nationes, incluídos nos Gallicani os espanhóis, os italianos e os orientais; os Angli (chamados alemani depois de 1230) abrangiam, além dos ingleses (preponderantes), escoceses e irlandeses, os escandinávios, húngaros, polacos, boêmios e alemães. Os Paises-Baixos se englobam em a nação dos Picardi.

Como se vê, a Universidade Parisiense é uma verdadeira e internacional universalidade. Característica de tôdas as universidades medievais, a cultura do espírito, como a fé religiosa do século XIII, é católica, no sentido etimológico do vocábulo. $\mathrm{Na}$ grande Alma Mater da pátria de São Luís brilham a um tempo mestres da estatura de Boaventura e Tomás de Aquino, italianos; Alberto Magno, teutónico; Sigério de Brabante, flamengo; Rogério Bacon e Duns Escoto, ânglicos. Cosmopolitismo bem compreendido, que explica a interpretação dos grandes centros de cultura e é um dos segrêdos dessa esplêndida civilização humana e cristã do século áureo da Idade Média. (8)

8. Cf. Jansisen, L'Allemagne à la fin du moyen âge, pág. 74: Qu'on ajout à cela le caractère international qu'avaient adors les hautes écoles; car, entre savants de toute l'Europe civilisée, un continuel courant était établi; d'incessants voyages, de fréquents échanges intellectuels mettaient en rapport, des hommes distingués de tous les pays. La culture de l'esprit recevait ainsi une vie, un developpement toujours nouveanux, et les esprits vraiment remarquables sortis des limites étroites de leur patrie, voyaient leur savoir devenir comme le trésor commun de tous ceux qui désiraient acquérir la Science. - As seguintes palavras de E. Faguet (Seizième Siècle, Paris, Lecéne, s. d., pág. 81), referentes a Rabelai,s e ao séc. XVI, não são menos exactas do séc. XIII: La science ou l'amour de la science $y$ était un passeport et un sauf-conduit. Dans chaque ville savant le lettré que arrive est chez lui; il a des pairs, des alliés des defenseurs et demain des disciples. II entre tout poudeux, il dit "Argumentabor", et s'il argument bien, il est du 
Os mestres em artes também, por excepção, pertencem às nationes, considerados alunos, por serem os estudos da Faculdade das Artes preparatórios aos das outras Faculdades. De certo modo, Faculdade de categoria inferior.

Cada nação elege, dentre os seus membros, um procurador, e os quatro procuradores elegem o Reitor. Êste, a princípio só da Faculdade das Artes (1274), passou depois a sê-lo também das de Medicina e Direito (1279) e, enfim, de Teologia (1341). Tornando-se assim a suprema autoridade universitária, depois de suplantado 0 Chanceler, cancellarius, representante do Papa e que se arrogava, em oposição ao Reitor, o direito de nomear professores e conferir graus académicos. Luta de cêrca de século e meio, acabou dando ao Reitor a vitória def́initiva.

Ficava assim a Universidade gozando de absoluta autonomia, totalmente independente do poder eclesiástico como do civil. Corporação de mestres e alunos, realiza o ideal do trabalho colectivo e continuado, condição essencial de sua fecundidade, impossível à limitada e efémera atividade individual e individualista. Como as grandes catedrais góticas, a organização universitária medieval, factor importante 'na edificação dessa outra arquitetural construção, a Filosofia Escolástica, é o produto do trabalho lento e diuturno de gerações (9).

Mas nem por isso fica eliminada a pessoa humana com o seu imprescritível atributo da liberdade: quem se julga

pays, du grand pays latin, qui s'étend du fond de l'Allemagne à Salamanque et de Paris à Salerne. - Cf. ainda Irsay, pág. 146: Toutes les universités $d u$ XIII siècle furent internationales. Allemands, Anglais, Ecossais et Irlandais, Italiens, Espagnols et Portugais, Grecs, et Hollandais (par importance) furent membres da Stadium parisien; et on retrouve des. conditions à prés analogues ailleurs.

9. Singuli ut singuli non possumus hoci facere, exorta o chanceler de Paris. Ao que nota Irsay, pág. 148: Comme ceci correspond bien au sentiment profond du moyen âge humiliant l’orgueil de l'individu, exaltant la communauté, la cité. 
apto a ensinar pode fazê-lo; e o estudante é adicto do mestre de sua liyre escolha.

A intervenção absorvente do Estado, o desorganizador por excelência da vida universitária, é fenómeno totalmente inconcebível na idade média; e estará talvez nisso o segrêdo do seu prodigioso êxito. "Nenhum Príncipe, nenhum Chanceler nada tem a ver com os nossos privilégios e as nossas liberdades", adverte João de Kone, professor da Universidade de Lípsia, em discurso público pronunciado em presença do Duque de Saxónia, em 1445. Podia tê-lo dito referindo-se às Universidades de Paris ou Oxónia, no século XIII, das quais não são menos verdadeiras as palavras de Zarncke: "A Universidade se governa por si mesma, ela própria transforma e melhora os seus estatutos, segundo suas necessidades" (10).

Mas a partir da Renascença e da Reforma, a Universidade perde a sua preciosa independência, transformando-se freqüentemente em dócil instrumento do poder civil na consecução dos seus fins políticos. Na época de esplendor, porém, totalmente inimaginável seria uma ins-, tituição universitária poder alienar os seus privilégios e, descendo do pedestal da livre pesquisa científica e filosófica desinteressada, enfeudar-se à luta partidária e in-

10. Apud Janssen, pág. 73. Na mesma página acrescenta Janssen: Les Universités du moyen-âge étaient des corporations libres, indépendantes, raison de leur succès, c'était la liberté sans entraves dont elles disposaient, liberté d'apprendre comme liberté d'enseigner. Indépendantes les unes des autres, indépendantes de l'État, ellẹs se developèrent dans émulation mutuelle, animée $e$ féconde. De même que dans les diverses corporations de métiers, maîtres et compagnons formaient un parfait ensemble, une association libre de toute influence exterieure, ayant ses propres lois et ses interêts séparés; de mếme les hautes écoles avaient de droit de s'organiser à leur guise: elles se completaient l'une par l'autre, et, fidèles à l'idéal de toute science vraiment libre, se composaient de membres jouissant des mêmes droits. Elles avaient le pouvoir presque illimité de faire les lois et de se donner à elles - - mếmes leurs statuts. 
glória na arena de efémeras e mesquinhas ambições temporais.

Nobre autonomia, que não significa todavia nenhuma oposição à autoridade secular e muito menos à eclesiástica. Neste último respeito, em particular, as universidades medievais mantêm para com a Santa Sé relações de cordial e generosa submissão. Nem poderia ser de outro modo, pois, das 44 universidades existentes antes de 1400, 31 receberam do Papa o breve de fundação, sendo 21 de sua criação exclusiva (11).

Longe, pois, de lhes prejudicar a independência e liberdade, estas encontram no Papa a suprema garantia. A Santa Sé nunca intervém na vida íntima dêsses institutos. Suas relações com as corporações universitárias versam sôbre cerimoniais e ritos académicos ou sôbre matéria legal e constitucional, como vimos. Quanto à distribuição dos estudos, reina a mais completa autonomia, e qualquer restrição sofrida na liberdade do ensino é sempre obra da opinião do próprio mundo universitário (12).

Não é, pois, de admirar que, filhas privilegiadas e queridas da Igreja, como escreve Wimpheling, as universidades retribuíssem com fidelidade e afeição o muito que lhe deviam (13).

Mas a égide e a vigilância do chefe supremo não priva os clerici da espontaneidade da vida.

11. Schnürer, pág. 542 .

12. Irsay, pág. 149-50.

13. Apud Janssen, pág. 72. Janssen pôde, assim, com verdade escrever. (ib.): Les Universités du moyen âge appartiennent aux créations les plus grandioses de l'esprit chrétien. Il s'y manifeste avec éclat, dans toute la fraicheur et la vigueur de la jeunesse. Elles furent les organes de la haute culture scientifique, le plus puissant lévier de son developpement ultérieur, la nation. les Universités, aussi longtemps que leur union à l'Église et a la foi ne subit aucune atteint parvinrent à leur plus haut point de splentdeur. - Janssen se refere à Alemanha, mas o trecho transcrito tem alcance geral. Como também pode aplicar-se ao séc. XIII o que Paulsen (pág. 30) refere das ordens religiosas na Alemanha dos 
Clérigos, clerici se chamavam mestres e alunos, por levarem um género de vida eclesiástica e trazerem vestes eclesiásticas. $\mathrm{O}$ que porém não significa tenham recebido ordens sacras. O atribuir-se essa denominação também aos leigos se explica pelas imunidades e privilégios que os clérigos, no sentido atual do vocábulo, desfrutam desde antes do nascimento das universidades, privilégios e imunidades estendidas depois aos leigos. Êstes, como os estudantes de Filosofia e Teologia, os mais numerosos e que usam vestes eclesiásticas, por terem em mira consagrar-se ao serviço da Igreja, também se vestem do hábito clerical, como prova externa das suas prerrogativas, embora sem nenhumas ordens sacras. Nem mesmo a simples tonsura, sinal de pertencerem à ordem eclesiástica, a tinham ĉles $\left(1 A_{n}\right)$.

O celibato é contudo obrigatório tanto para docentes como para discentes de tôdas as faculdades, não só em Paris como em Bolonha. Em Paris o cardial Estouteville, em 1452, desligou dessa obrigação os professores da Faculdade de Medicina e os de Leis só o foram pelos estaiutos de 1600.

$\mathrm{Na}$ Faculdade das Artes scolares e magistri vivem juntos sob disciplina claustral, nos edifícios e colégios da universidade. Morar fora (como os martinets, no séc. XV), stantiam hohere extra locum probatum, é em regra proibido. Os clerici seculares muitas vezes se reunem e vivem num hospicium, sob a direcção de um principal, bacharel ou doutor, eleito por êles. Os clerici regulares residem nos respectivos conventos: os dominicanos se estabeleceram

sécs. XIV e XV: Gerade im 14. und 15. Jahrhundert ist die Kultur der eigentlichen, Wissenschaften in Deutschland eimheimisch geworden; es waren Kleriker, welche sie aus der Fremde holten und in der Heimat anpflanzten und pflegten.

14. Savigny aduz como prova de significar clericus 0 estudante leigo, que os estudantes de Paris são chamados clericî scolares e os livreiros, clerici librarii (pág. 140 n. f.) 
em Paris em 1217, os franciscanos em 1230, vindo depois os carmelitas e agostinhos.

Como medida discipìinar recorre-se às vezes à flagelação: o delinqüente a sofre nas espáduas nuas, perante o Reitor e os Procuradores (15).

Mas, como adverte Schnürer, a Universidade, no seıı conjunto apresenta um carácter eclesiástico, submetida à influência da Igreja e sendo o fim principal do ensino a formação do clero (16).

Apesar disso, contudo, nem sempre é modelar a vida do estudante. Em documento que se pode ler no Chartularium de Denifle (17) e datado de 1269, há queixas contra "certos clérigos e estudantes que, acompanhados dos criados, noite e dia ferem, matam, raptam mulheres, violam donzelas, pilham estalagens, roubam e cometem tôda espécie de celeradês e impiedade". Não menos desedificante é o que relata o Chanceler Prévostin: "L'étudiant ès aris court la nuit tout armé dans les rues, brise la porte des maisons, remplit les tribinaux du bruit de ses esclandres. Tou le jour, des meretriculae viennent déposer contre lui, s: plaignant d'avoir été frappées, d'avoir eu leurs vêtenınts mis en pièces ou leurs cheveux coupés." Isso mesmo corrobora um pregador coevo: "Il y a des étudiants qui passent leur temps $\dot{a}$ boire dans les tavernes, $\dot{a}$ fabriquer des chàteaux en Espagne et qui changent les classes en dortoirs."

Freqüentes as rixas entre estudantes de nações diversas; entre estudantes e burgueses, quando êstes lhes violassem os privilégios e imunidades.

Dêsses conflitos, sobretudo com a burguesia e o muni. cápio, originavam-se as mïgrações de mestres e alunos; e assim, como por cissiparidade, iam formar novos studix em outras cidades. Em 1229 Paris sofreu uma dessas seccessões. De novo, em 1231, como conseqüência de conflitos em que-

15. Cf. Savigny, III, pág. 258 e Paulsen, pág. 34 .

16. Schnürer, pág. 549 .

17. Chartularium, I, 48, n. 426 apud Schnürer, 549. 
morreram vários estudante, a universitas, clericorum deseruit Parisiis, e os cursos se interromperam. E quando não chegassem até tal extremo, podiam declarar-se em greve, direito que lhes reconheceu formalmente Gregório IX.

Muitos estudantes eram vagantes, errando de uma universidade para outra, clientes das tabernas e da caridade pública, entregues ao furto ou feitos menestréis, a trovar por onde prassavam. Espécie de proletariado inteleciual, escandalizavam Alano de Lille, que assim os pinta: Potius dideiti gulae quam gloriae, potius colligunt libras quam legunt libros, libentius intuentur Martham quam Marcuin, malunt legere in salmone quam in Salomone (18).

Nasceu nêsse ambiente a poesia jocosa chamada goliárdica e os carmina burana (19). E' conhecida a composição onde se lê a quadra seguinte, continuada por outras do mesmo estro:

Meum est propositum in taberna mori: ut sint vina proxime morientis ori.

Tunc cantabunt laetius angelorum choris

"Deus sit propitius huic potatori." (20).

A Igreja opôs tenaz resistência, mas sem grande resultado, a essa população dissoluta e vagabunda, na qual se contavam não poucos eclesiásticos. $O$ que fàcilmente se compreenderá, observa Schnürer, atendendo-se a que a Igreja, sendo, como era, a detentora e distribuidora da instrução na Idade Média, os jovens de origem modesta não podiam

(18). Irsaf, pág. 159, n. 6.

(19) Cf. a colecção De nugis curialium, atribuida a Walter Map, Oxford, 1914 e Carmina burana, Stuttgart, 1847. - M. Rodrigues Lapa, Das origens da poesia lírica em portugal na Idade-Média, Lisboa, ed. do autor, 1929, pág. 156.

(20) Les Poètes Goliardes, pg. 491. - Cf. Baumartner, Alexander, Geschichte der Weltliteratur, IV er. Bd., Die lateinische und griechische Literatur der christlichen Völker, Herder, Freiburg, .S. 414 . 
esperar melhor situação que abraçar a vida eclesiástica. - Muitos o faziam levados de ambição puramente secular, sem verdadeira vocação; e iam assim muitas vezes, sentindo-se transviados, aumentar o número dos clerici vagantes. Razão explicativa do descredito em que caíu a Igreja no fim da Idade Média (21).

Escusado é dizer, que êsses desregramentos de vida constituem excepção. Em regra, longos e árduos estudos, cerradas discussões públicas e provas laboriosas absorvem as actividades do maior número. $\mathrm{E}$ quando se fundaram os collegia a disciplina subiu de nível (22).

Demais, a idade juvenil em que se começavam os estudos era propícia à formaçã̃o de hábitos disciplinados: entre 12 e 15 anos é a admissão à universidade; os graus se con-. ferem entre 20 e 21 anos; o candidato a doutor deve ser maior de 30 anos.

$O$ ano escolar se estende de 1 de Outubro a fins de Junho. Natal, Páscoa e Pentecostes trazem curtas interrupções aos trabalhos escolares. No verão, as grandes férias.

No decurso do ano lectivo os professores devem usar os livros prescritos no princípio, pelo regulamento da respec-

(21). Schnürer, pág. 550 .

(22) Pace nota com acêrto: The earlier university regulations dealt chiefly with adademic matters, leaving the students quite free in others respects. According to all acounts this freedom meant licence in various forms-fighting, drinking, and graver offences against morality. With due allowance for the exagerations of some writers who charge the scholars with every crime, it is clear from the college statutes that there was much need or reform. It should, however, be remembered thal in any age the boisterous and lawiess elements are more conspicuous than the serious, conscientious student; and it is doubtless to the credit of the medieval university, as a social factor, that it succeded in imposing some sort of discipline upper the motley thrangs which it undertook to teaci. E Pace recorda que, quando veio, a reforma quase reduziu a vida estudantil a uma ivida monática. Mas apesar disso não conseguiu estirpar certas práticas como a iniciação ou deposição do bejaunus (bec jaune), "the modern forme of hazing", acrescenta. 
tiva Faculdade. São êles: para a Teologia, a Bíblia e as Sentenças do Lombardo; para o Direito Civil, o Digesto e o Código; para o Direito Canónico, o Decretum Gratiani, as Decretais de Gregório IX, as Clementinas e as Extravagantes (23) ; para a Medicina - Galeno e Avicena, acompanhados de cursos práticos de anatomia; para a Filosofia, entre outros, a Vetus Logica, Prisciano, a Logica Nova, a Ethica ad Nichomachum, a Physica, a Metaphysica de Aristóteles (24).

Os mestres lêem os textos. E' a praelectio (palavra que o alemão traduziu em Vorlesung e que transparece no inglês lecture), acompanhada pelos estudantes em cópias de um manuscrito tipo chamado exemplar, composto de quatro fôlhas, quaternus ou pecia, e depositado pelo seu autor nas livrarias dos stationarii. A universidade taxa o preço dessas cópias (25). Se o estudante por pobreza não as prode adquirir, o professor lhe dita o texto em cursos de repetição.

A praelectio consiste em ponere et determinare, i. e., explanar e definir os termos; scindere et summare, ou divisão da matéria seguida de um sumário dos pontos essenciais; enfim as quaestiones ou apresentação e solução dos problemas sugeridos pelos textos. Uma fórmula mnemónica, aplicada ao Direito pode ser estendida à Filosofia:

(23) O Decretum Gratiani é assim chamado por ser obra de um monge camáldulo do mosteiro de S. Filipe, em Bolonha; veio substituir o ius antiquum, como sistematizacão do direito canónico tal como existia no principio do séc. XII. Publicado em 1140, foi o ponto de partida para uma multidão de decretistas. Assim, as Decretais são umas adições ao Decretum, bem como as Extra, compiladas por S. Raimundo de Penaforte, canonista catalão dominicano; foram enviados a tôdas as universidades em 1234, por Gregório IX pela bula Rex Pacificus. As Clementinae são uma codificação preparada por Clemente V e publicada em 1317 pelo seu sucessor João XXII. As Extravagantes são de João XXII, colecionadas em 1325 por Zenelin de Cassanis.

(24) Cf. para maiores desenvolvimentos, De Wulf, II, pág. 12.

(25) Cif. De Wulf, pág. 16 e Savigny, III, pág 407 e segs. 
Praemitto, scindo, summo, casumque figuro.

Perlego, do causas, connecto, objicio. (26)

As lecturae são ordinariae, quando feitas pelos doutores e de manhã; extraordinariae ou cursoriae, pelos magistri ou pelos baccalari à tarde.

Ao contrário do que se dá nas lições ordinárias, os estudantes podem, nas extraordinárias, propor dúvidas e objecções conducentes à melhor compreensão da matéria.

Parte capital do ensino, as disputationes; podem ser ordinariae e quodlibetales. A disputatio ordinaria e semanal dura da manhã ao meio-dia ou até à tarde, sendo avultado o número dos participantes. Um dos mestres, o dispu-. tans, formula a tese a ser discutida, e os opponentes objetam em sentido contrário. Dois ou três respondentes, batcallari, prara tal designados, resolvem as objecções, tudo em forma silogística e em latim (27). As Quaestiones disputatae de S. Tomás dão idéia clara do teor dessas discussões.

As quaestiones quodlibetales ou de quolibet realizam-se pela Páscoa e pelo Natal (quodlibet de Paschoa, de Natali). Na Faculdade das Artes essas discussões são nos seus locais, in vico Ttraminis (a célebre rue du Fouarre) a que Dante se refere (28), e atraem numerosa assistência. o quodlibetarius, mestre incumbido de debater a questão, tem como

(26) Paulsen, pág. 39, onde o leitor poderá ver o significado dêsses tèrmos.

(27) Referindo-se ao latim escolástico medieval, Paulsen escreve muito sensatamente: "a censura repetida até a náusea pelos antigos e modernos humanistas que Cicero não teria entendido th! iingua, (os escolásticos) haveriam de rejeitá-la como descabidamente tôla; pois que pretendiam era serem dêstes entendidos. $\mathrm{E}$ teriam podido acrescentar, que abandonavam de bom grado a língua pobre de Cicero como de todo insuficiente a exprimir suas subtis indagações sôbre as relações das idéias entre si; para adejar em tôrno das coisas com os seus quasi e quidam talvez a lingua ciceroniana pudesse servir, mas é totalmente incapaz de exprimir idéias com agudeza e precisão.” Op. cit., pág. 46.

(28) Parad. X, 137: Vico degli strami. 
opoentes os designados numa lista. Tais discussões podem durar vários dias e mesmo uma semana. As Quaestiones quodlibetales de Santo Tomás servem de amostra delas.

Essas árduas provas, com os exames a serem prestados, conduzem o estudante à conquista dos graus. Os exames são orais, passados perante o Chanceler e o seu júri, devendo o estudante responder com êxito a três ou quatro per. guntas, sob pena de reprovação, devendo neste caso tornar a comparecer depois de um ano. Mas, aprovado, obtém ao cabo de um ano de estudos o gráu de baccalareus; ao fim do segundo, o de licenciatus; coroa o curso, ao termo do terceiro, com o título de doctor ou magister Títulos que, na Faculdade de Teologia, corresponde aos de baccalareus biblicus, sententiarius e formatus (29).

Os magistri são actu regentes ou non regentes, segundo abandonam, no último caso, a carreira, depois da lição inaugural ou, no primeiro, dão cursos regulares depois de devidamente nomeados pelas faculdades, ou por estas com a aquiescência do Bispo, ou pelo Capítulo. Não se deve porém esquecer, que, em virtude do princípio da absoluta liberdade, característica do ensino universitário medieval, quem obteve o doutorado pode abrir escola e ensinar (30) .

O ensino começou por ser gratuito: Nas Siete Partidas, p. ex., Afonso-o-Sábio assim o dispõe: Ciencia es don de Dios y por ende non debe ser vendida; ca asi como aquellos que la han la habieron sin precio e por gracia de Dios, asi la deben ellos dar á los otros de grado, non les tomando por ende ninguna cosa (31).

A gratuidade era já tradição nas escolas catedirais e monacais do sec. XII. No séc. XIII os professores vivem das Pace.

(29) G. Irsay, pág. 150; Paulsen pág. 35; De Wulf, pág. 13;

(30) Cf. Paulsen, págs. 4rân-3 sôbre o valor do ensino.

(31) Pte. I, tít. XVIII, leg. X, ed. Madrid 1807, I, 431, apud Irsay, pág. 152. 
suas prebendas ou, quando religiosos, são sustentados pelas respectivas ordens; ou ainda, buscam meios de vida no exercício de uma profissão.

A Universidade é pobre, não tem aulas; nem outro recurso têm as Faculdades senão a taxa paga pelos estudantes para a obtenção dos graus. Os artistas se reunem na igreja S. Julien des Pauvres; os teólogos, nos Mathurins; os médicos, na casa do deão.

Ricos doadores criam os colégios universitários - collegia, studia dotata, onde os estudantes pobres têm garantidas cama e mesa (32). O mais famoso dêsses colégios foi a Sorbona, fundada em 1257 pielo capelão de São Luís, Roberto de Sorbon. Desde os fins do séc. XIV constituíu a Sorbona a Faculdade de Teologia, funcionando em edifício próprio. Deu o nome a essa Faculdade e, desde o comêço do séc. XIX, à Faculdade de Ciências e Letras e a quási tôda a Universidade.

(32) Referindo-se aos estudantes pobres medievais com vócação para os estudos, diz Paulsen: "Outrora a mocidade pobre não conhecia os tormentos do amor próprio dos tempos modernos. A frlta de fortuna não era causa de desfavor. Ao contrário, muitas mãos se estendiam em socorro do estudante sem recursos. Em todos os estabelecimentos eclesiásticos, i. é, em tôdas as casas de ensino, colegiais, escolas monásticas, ginásios, universidades, os pobres gozam, como dizem os estatutos de Viena, do privilégio "do bom querer." Admitiam-nos gratuitamente, tanto à matrícula como aos cursos e às promoções. Um sem-número de fundações, de donativos eram feitos em favor dos jovens desprovidos de recursos. Além disso, nas escolas secundárias, a mendicidade passava por meio regular de ocorrer às despesas, e não era excluida de todo das universidades. Como poderia a mendicidade tisnar a honra dessas sociedades, que recebiam no seu seio tantos membros das ordens mendicantes, obrigados por delver de estado a pedir esmolas? No pensamento da Igreja, nisso muito conforme ao do Evangelho, a riqueza e o bem-estar pareciam muito mais perigosos para a vocação que a pobreza e a mendicidade. Todo estudante pobre era pois livre de ganhar a vida colocando-se ao serviço de outrem. Mui frequentemente os sábios recebiam os serviços pessoais dêsses jovens 
Para diferenciá-los das casas religiosas, onde vivem os estudantes regulares, os collegia eram chamados bursae, de bursa, que significa bôlsa, bôlso, saco. O vocábulo veio a estender-se ao lugar gratuito no colégio, depois ao próprio colégio. O beneficiário de uma bursa é bursarius, bursiatus, donde a palvra alemã Bursch, rapaz.

Embora houvesse estudantes abastados, filhos da nobreza e da burguesia, é exacto afirmar-se que a população universitária é antes pobre. Mais de um professor se vê obrigado a penhorar os livros; e certos inventários publicados no Chartularium deixam patente a vida modesta de muitos mestres ilustres.

Tamanha importância assumiram os collegia em Oxford e Cambridge, que vieram eles, a constituir e a absorver a Universidade. Em Paris, ao contrário, a Universidade os absorveu.

\section{I. - A Universidade de Bolonha.}

Como Paris para as Artes e a Teologia, Bolonha é o grande centro dos estudos jurídicos; Bononia docet. (34) Mas diversamente da alma mater parisiense, que é uma universitas magistrorum, a Universidade de Bolonha e̋ uma corporação de estudantes estrangeiros, advenae forenses, que nomeiam os seus chefes, a quem obedecem os professores. Homens de idade já amadurecida, os scolares se organizam em corporações, à imitação dos guilds de trafi-

sem recursos. O trabalho não passava de nenhum modo por desonroso na Idade Média, e os estudantes não se sentiam humilhados desempenhando o oficio de criados de seus amos, como o pagem não pensava rebaixar-se servindo ao senhor. Esse estado de coisas tornava possível recrutar o clero na massa do povo; não havia nas universidades e nas escolas latinas nenhuma condição que não fosse representada" - Apud Janssen, pág. 73, nota 2.

(33) V. em Paulsen a vida errante e penosa de Zengg, segundo Burckhardt, pág. 26 e segs.

(34) Cf. Schnürer, pág. 543. 
cantes, para mutuamente se auxiliarem e obviarem às necessidades da vida.

Pondo de parte tradições lendárias, que fazem a Universidade coeva de S. Ambrósio, o primeiro documento histórico que se the refere é a autêntica Habita, de Novembro de 1158, pela qual, na dieta de Roncalha, perto de Placência, o Imperador Frederico I, o Barba-Roxa, concede aos estudantes estrangeiros, qui causa studiorum peregrinantur, e aos professores, sobretudo de Direito, et maxime divinarum atque sacrarum legun professoribus, que possam habitar a cidade e freqüentar em paz os cursos, ut ad loca, in quibus literarum exercentur studia, tam ipsi quam eorum nuntii veniant et habitent in eis secure. O Imperador assim o dispõe compadecido dêsses que amore scientie facti exules de divitibus pauperes semet ipsos exinaniunt, vitam suam multis periculis exponunt et a vilissimis sepe hominibus, quod graviter ferendum est, corporales iniurias sine causa perferunt (35). Concede-lhes foro privilegiado: Veruntamen si eis litem super aliquo negotio quispiam movere voluerit, huius rei aptione data scolaribus eos coram domino aut magistro sua vel ipsius eivitatis episcopo, quibus hanc iurisdictionem dedimus, conveniant (36). Nos fins do sec. XII a êsses três juízes se acrescenta um quarto, o Reitor, que se firma como autoridade e a quem mestres e discípulos podem deferir o conhecimento das suas pendências.

Em Bolonha a princípio ensina-se só o Direito; depois, em 1316, surgem as Faculdades de Filosofia - philosophi ou artistae, e de Medicina - medici ou physici; finalmente, a

(35) Em 1155 os estudantes haviam recorrido ao seu auxílio: Unde, mater, petimus perversum corrige morem.

Lego tua liceat tutos hic esse legentes - Apud Irsay, pág. 90, n. 4.

(36) A authentica na sua integra foi acrescentada ao Código de Justiniano, em 4. XIII, ne filius pro patre. $\mathrm{Na}$ ed. de Paulo Krueger vem à pág. 511 . 
Faculade de Teologia em 1362, criada por bula de Inocêncio IV.

Mas já na primeira metade do sec. XIII os estudantes estrangeiros de direito, ultramontani, separam-se dos italianos, citramontani, e a Faculdade cinde-se em duas: a universitas ultramontanorum a universitas citramontanorum. São os advenae forenses porém que, com o Reitor, à frente, constituem verdadeiramente a universitas, em virtude do privilégio de Frederico I. Por isso os naturais de Bolonha não têm voz nas assembléias nem podem exercerqualquer função universitária.

Como em Paris, os estud'antes se agrupam em nationes: 17 dos citramontanos e 18 dos ultramontanos. Os dêstes últimos compreendiam segundo os estatutos: Gallia, Portugallia, Provincia, Anglia, Borgondia, Sabaudia, Vasconia et Alvernia, Bicturia, Turonenses, Castella, Aragonia, Catalonia, Navaria, Alamania, Ungaria, Polonia, Boemia, Flandrenses. Um mundo internacional, como em Paris.

Os alemães Theotonici, cêrca de uma centena no fim do. sec. XIII, a maior parte eclesiásticos e de idade madura, buscam o título de doctor, diz Schnürer, para com êle alcançarem na pátria empregos e honras. Gozam do privilégio de prestar juramento nas mãos dos Procuradores e não nas do Reitor, e elegem quinquenalmente o Reitor dos ultramontanos. Os estudos, visando evitar gastos excessivos e danosos aos estudantes, determinam o hábito que devem trazer na cidade ou no distrito de Bolonha. Vestuário talar e de aspecto eclesiástico (37).

(37) Stat. 3. 52. Diamnosis sclollarium sumptibus providere cupientes statuimus quod nullus scolaris in civitate Bononae vel ejus districtu emat per se vel per alium pannum alium quam pannum. qui vulgariter vocatur pannus de statute vel de panno coloris nigri; quem pannum pro habitu superiori, cappa tabardo vel gabano vel consimiti veste consueta pro tune longiori veste inferiori, et clausa a lateribus ac etiam fibulata seu maspillata anterius circa collum portare teneantur intra civitatem sub poena trium lib. Rect, effectualiter exigenda. 
Autoridade universitária suprema, o Reitor deve ser clericus, i. é, estudante, celibatário, de 25 anos, não pertencera nenhuma ordem religiosa, dono de fortuna suficiente e ter estudado Direito ao menos durante cinco anos (38). O seu mandato é de um ano. Gozando da mais alta consideração, tem precedencia sôbre o Arcediago de Bolonha, sôbre Bispos e Arcebispos, menos sôbre o Bispo de Bolonha. Exerce: jurisdição civil e criminal sôbre todos os membros da Universidade, excepto sôbre os estudantes alemães.

Ao lado do Reitor, certa autoridade foi conferida por um decreto de Honório III, em 1219, ao Arcediago de Bolonha, depois chamado cancellarius, como em Paris. Por êsse decreto nenhuma promoção podia ser feita sem um exame. prévio e com o assentimento do Arcediago, para evitar $\boldsymbol{x}$ promoção de candidatos indignos.

Feito depois cancellarius, o Arcediago interfere nas promoções de tôdas as Faculdades, menos nas de Teologia, dependendo do Bispo, cujo encargo, nêsse ponto, foi chamado cancellariatus.

(38) Stat, I. 1.: Ad Rectoratus igitur officium eligatur Scolaris nostrae universitatis qui vita et moribus gravis: honestus, quietus et justus; et pro bono communi universitatis magis commendandus existat Item sit clericus non congregatus habitum deferens ctericalem ac nullius religionis appareat. Super quibus vel aliquo. praedictorum nullatenus dispensetur .. Et qui ad minus quinque annis juri studuerit in studiis generalibus, et suis propriis sumptibus continuo vixerit; et vigesimum quintum annum suae a'tatis attige-rit. - A expressão clericus non congregatus, mostra à evidência o sentido, referido no têxto, dêsse vocábulo. Os Statuta, 2. 35, determinam a ordem em que se fará o estudo dessas diversas partes e dispõe rigorosamente sôbre o principio e o fim dos lectiones. Leia-se, por ex., isto: doctores tam in jure canonico quam civili de mane legentes intrare debeant in campana sancti Petri quae pulsatur de mane vel ante si is videbitur. Nec audeat tardare ad veniendum post pulsationem dicte campane ad scolas poena XX solid. cuilibiet imminente pro qualibiet vice qua contrarium fecerint - o mesmo se dispõe para o fim da praelectio. 
Desde então, nota Savigny, a quem vamos seguindo em tôda esta exposição, o Papa considera o Arcediago chefe da escola, e a êle se dirige no concernente à Universidade.

Mas em 1270 os doutores se opõem às prerrogativas do Chanceler, entregando-se na igreja a actos de violência contra êle e o Bispo. Logo prorém se submetem e o Chanceler continua no exercício pacífico de suas funções. Não houve, pois, em Bolonha, como em Paris, lutas prolongadas entre as duas autoridades universitárias.

De certas questões o Reitor toma conhecimento juntamente com o senado dos consiliarii, representantes das nationes, um ou dois para cada uma delas. Os consiliarii dos alemães, chamados procuradores, exercem a jurisdição sôbre êles, com exclusão do Reitor e das autoridades munipais.

São ainda autoridades universitárias o syndicus, o notarâus e os dois bidelli.

O syndicus, eleito anualmente pelos estudantes, representa em justiça as duas Universidades. O notarius e o massarius também eleitos anualmente: aquêle, pelos notários da cidade, e êste, espécie de caixa, pelos negociantes. Dois bidelli, um para cada universidade, renovados anualmente.

Entre os mais funcionários universitários, ocupam lugar importante os peciarii e os stationarii. Os peciarii, em número de três para cada uma das duas Universidades -- devem velar pela correcção das peciae. Chamava-se pecia, em Bolonha e em Pádua, explica Savigny (III, pág. 408), o manuscrito composto de duas folhas inteiras ou de quatro meias fôlhas ou de meio quaternus; cada página era dividida' em duas colunas num total de dezesseis, tendo cada coluna sessenta e duas linhas e cada linha trinta e duas letras. De pecia veio o italiano pezza e o português peça. Na pecia estava escrito o texto que serviria às prelectiones; constituia o exemplar, depositado na loja de um stationarius, ou livreiro, que dêle tirava cópias para vender aos estudantes. Os stationarii deviam ter exemplares correctos, vender ou alu- 
gar as cópias pelos preços taxados pela Universidade, e não vendề-las nunca a uma escola estrangeira (39).

Professores e estudantes desfrutam de privilégios determinados pelos estatutos. Os estrangeiros são equiparados aos cidadãos, mas têm, como vimos, o privilegium fori. Os professores bolonheses são isentos de todo imposto e do serviço militar.

Investidos na sua dignidade, juram os magistri não haverem nunca de ensinar fora de Bolonha. E o cidadão que persuadisse a abandonar a Universidade um estudante, um professor bolonhês de mais de cinquenta anos ou os professores salariados, antes de findo o prazo do contracto, sofria pena de morte e confisco dos bens.

Dificuldades sôbre preços de alojamentos são dirimidas por quatro taxadores, nomeados anualmente, dois pela cidade e dois pelos estudantes.

Era uso antigo fazerem os estudantes, ao cair das primeiras neves, uma colecta entre os doutores e cidadãos ricos, com o fim de pagarem os retratos ou as estátuas de celebridades professorais, com os quais ornavam os locais universitários.

Como em Paris e Oxford, a organização dos collegia veio em auxílio dos estudantes pobres. A expressão collegium é já empregada antes de 1302. Em 1263 é criado o collegium avenonense; o Brixiense, em 1330 em 1364, o Hispanicum, cujo edifício até hoje subsiste, pelo cardial Egídio Albornoz.

O ano lectivo de 19 de Outubro a 6 de Setembro. A 7 vigília da Natividade, é o inlício das grandes férias; além das quais, quinze dias pela Páscoa e onze pelo Natal. Inicia-se cada curso por missa solene e um discurso pronunciado por um estudante ou, na falta dêste, por um professor de humanidades.

(39) Cf. Stat. I, 18. De petiariis et eorum officio; I, 26 e 27 sôbre os stationarii e os preços dos livros. Ib., 4, 68, sôbre os stationarii que têm os exemplaria. 
Os cursos são ordinários ou extraordinários, ordinariae et extraordinariae lecturae. Distinção de sentido controverso, parece correlata, no pensar de Savigny, aos livros usados, que são ordínários e extraordinários. Os cursos sôbre livros ordinários são extraordinários quando dados à tarde. Os livros ordinários para o Direito Romano são o Digestum vetus e o Codex; os extraordinários, o Digestum novum, o Informatiatum e o Volumen (40). Para o Direito Conónico o Decretum (Gratiani) e as Decretales.

Professores ordinários, que dão os cursos ordinários, podem dar os extraordinários; mas professores extraordinários só podem dar cursos extraordinários. Por aula que faltem pagam duas libras de multa.

Aos cursos ordinários, os mais importantes e seguidos assiduamente por todos os alunos, destinam-se as horas matinais, propícias ao trabalho fecundo. Dos extraordinários, os estudantes seguem os que melhor lhes aprouver.

As repetitiones e disputationes servem de complementos. Aquelas, que duravam do comêço do ano até ao Carnaval consistem na explicação minuciosa de um texto, acompanhada da solução das dificuldades e das respostas a tôdas as objecções. Estas, da Quaresma a Pentecostes, semanalmente e nos dias sem curso, salvo as festas solenes, e delas só podem participar os doutores e os estudantes candidatos ao ensino salariado. $O$ tema é um ponto de direito; todos os bacharéis devem assistir aos debates e todos os estudantes.

(40) Os romanistas medielvais assim repartiam as Pandectas: 1. Digestum vetus, até o liv. 24, tit. II, de Divortis - 2. O Infortiatum, do liv. 24, tit. III, de soluto matrimonio, até o fim do liv. 38 - 3. Digestum novum, desde o liv. 39, tit. I, de operis novi nunciatione, até o fim do Digesto. - Dividiam o Corpus Juris Civilis em 5 volumina: os três primeiros abrangiam o Digesto; o 4.०, os 9 primeiros livros do Código; o 5. ${ }^{\circ}$, chamado Volumen, por falta de nome próprio, compreendia os 4 livros das Institutiones, as 9 collationes das Authenticae, a coleção do Direito Feudal com um certo número de constituições imperiais formando tudo a 10. collatio. Os liv. 10 . 11 e 12 do Codex são chamados Tres Libri. 
podem objectar. Os assuntos, tanto das repetiones como das disputationes hão-se de publicar com vários dias de antecedência e sua explicação completa será entregue dentro de um mês ao bidellus da Universidade. O alvo visado pelo estudante nêsse longo e acidentado curriculum é o título de doctor, sinónimo de magister no séc. XIII. Porque, antes, o doutorado era designativo de um grau, não dando ao doutor o privilégio de ensinar, pois magistri havia sem serem doctores (41).

Os professores obtêm o doutorado em Direito Romano, depois de oito anos de estudo; em Direito Canónico, de seis. Podem obtê-lo também in utroque jure.

O candidato ao doutorado deve afirmar, sob juramento, ter perfeito o tempo prescrito de estudos, e ser apresentado ao Arcediago ou Chanceler por um doutor.

Passara antes por duas espécies de exames: privata examinatio e publica examinatio.

Antes do exame indicam-se ao candidato, ad rigorosum et tremendum examen transire cupientes, dizem os Estatutos (2.41) dois têxtos, puncta assignala, a serem tratados: de Direito Romano, de Dirento Canónico, ou de ambos, segundo queria obter o doutorado em uma só dessas disciplinas ou nas duas (42).

No mesmo dia lê a sua dissertação, sendo arguído pelo doutor que o apresentou e por outros, devendo êstes últimos jurar que não tiveram nenhum entendimento prévio com o examinando. E' obrigação dos examinadores tratar o caudidato como se fôsse filho, sob a pena regulamentar de um ano de suspensão. Aprovado, em escrutínio secreto, recebe - grau de licenciatus, que não lhe dá nenhum privilégio sôbre os mais estudantes, servindo a licença apenas de transição para o doutorado (43).

(41) Savigny o prova sem réplicas em I, § 136.

(42) Stat. 2. 41, De punctis in privata examinatione.

(43) Stat., 2. 41: Examinatione vero finita antequam doctores innde recedant, fiant solito more scrutinium sigillatim et secrete, 
Terminadas tôdas essas provas, examinadores e examinado dirigem-se solenemente para a Catedral, onde se realiza o conventus, perante o qual o licenciado pronuncia um discurso, e lê uma tese de direito, sendo arguído só por estudantes. Proclamado então Doutor pelo cancelarius, ou pelo Doutor que o paraninfou, recebe o livro, o anel e o barrete doutoral, insígnias de sua nova dignidade, e é convidado a sentar-se na cátedra.

Como antes do exame já havia jurado, perante o Reitor, que fez o curriculum regulamentar de estudos e nada mais pagou além das taxas prescritas, antes do conventus repete êsse juramento e mais, que nunca procederá contra a Unjversidade nem contra os estudantes e obedecerá ao Reitor e aos estatutos. Compromete-se sobretudo a não deixar a Universidade; mas êste juramento foi abolido em 1312 e desde então um decreto do Papa garante aos doutores de Bolonha o jus ubique docendi.

Esse complexo de solenidades e a aquisição do título de doutor implicava para o candidato em não pequenas despesas; como chegassem a ser excessivas, o Papa ordenou esn 1311 não deveriam sobrepujar 500 libras, uns 2.350 francos, na avaliação de Savigny.

Os doutores que realmente exercerem o ensino são le.. gentes; os que abrem mão dessa prerrogativa, non legentes. Mas quando os cursos ordinários vieram a pertencer exclu. sivamente aos cidadãos de Bolonha, houve baccalari, ao lado e doutores legentes ordinários e extraordinários, e que só podiam fazer cursos extraordinários salariados, previstos em decreto. Mas antes, o estudante que professou uma obra inteira de Direito Canónico ou Civil, ou sustentou uma repetitio solene sôbre um fragmento do Direito Civil ou Canónico, era Bacharel. O bacharelado, pois, conclui Savi-

quo quisque deponat an approbet vel reprobet examinatum...Ifem statuimus quod nullus Doctor in privata vel publica vel ejus occasione aliter tractet scolarem quam suum filium faceret proprium sub poena contra injuriantes scolaribus impositas et perjurii. 
gny, não é um grau acadêmico conferido pela Faculdade nem um emprêgo acadêmico conferido pela Faculdade, diferentemente do que se passava em Paris' (44).

Cursos públicos pagos pelos estudantes e professados por mestres estrangeiros tornaram-se, desde 1289, instituição permanente. Esses professores salariados porém gozavam menos consideração que os outros. Em 1384 a cidade pagava 19 juristas e 23 artistas. Por fim, todos os professores são salariados e professorado se considera função pública.

Vencimentos também eram previstos para certas cadeiras ensinadas por estudantes estrangeiros. Eram elas: ordinaria in Decretis, extraordinaria in Decretis, Sexti et Clementinarum, Infortiati et Novi pro diebus festis continuis, Voluminis, Infortiati et novi pro diebus festivis.

No séc. 13 os locais dos cursos são as salas, scolae, alugadas pelos doutores; sendo os alunos muitos, são dadøs num edifício público.

Savigny observa, terminando o estudo dos estatutos da Universidade de Bolonha, que as relações entre mestres e alunos eram mais exclusivas e menos efémeras que hoje. Um estudante é o adicto de um só professor a quem êste podia chamar seu alumnus, no sentido etimológico do vocábulo (alo) (45). Mas essas relações nem sempre são irrepreensíveis. Certos doutores não têm escrúpulos em emprestar dinheiro aos estudantes, para depois aumentarem os ordenados. Doutores novos, para conseguirem mais numeroso auditório e reputação, fazem o mesmo e assim lhes aumentavam os honorários. Em 1279, refere Savigny, Egídio não podendo, por doença, professar sôbre as decre-

(44) Stat. 2. 40: ... et pro baccalariis haberi etiam non aliter, qui legendo prosecuti fuerint lectiones alicuius libri juris canonici vel civilis canonici vel civilis, vel legem aliquam; seu decretalem repetierint publice cum oppositis et quaesitis.

(45) Cino, romanista que nasceu em Pistóia em 1270 (CF. Savigny, IV, 213), referindo-se ao seu mestre Lambertino Ramponense, diz sub quo militare volui. 
tais, aluga a Garsias, pela metade dos honorários, sala e auditório. Em 1295 um professor de Lógica compromete-se a ensinar três anos e dar a um profesisor de Filosofia o quarto dos honorários, com a condição de êste ensinar três anos na mesma sala e dar-lhe o têrço dos honorários superiores a 40 soldos e do que cada estudante pagasse até 30 soldos. Como se vê, vem de longe a luta entre a ambição e o direito.

\section{III. - A Universidade de Oxford.}

Universitas Oxoniensis é designativo que aparece desde 1252. Como a Universidade de Bolonha, também, a de Oxford tem suas origens embaladas pela lenda. Um cronista a faz contemporânea de Samuel, juiz na Judéia, enquanto outro sabe de ciência certa ter sido o studium oxoniense fundado por uns filósofos, quando guerreiros troianos, chefiados por Bruto, apoderaram-se das ilhas de Albion! Não falta quem considere seu verdadeiro fundador - rei Alfredo-o-Grande. O que parece fora de dúvida é terem ensinado em Oxford, desde a primeira metade do séc. XII, certos mestres como Teobaldo Estampense, Adelardo Batense, o famoso criador da teoria do respectus, e Roberto Pullen, autor das Sententiae, modêlo das que mais tarde escreveu Pedro Lombardo. Também o célebre mestre lombardo Vacário, Magister Vacarius, ai introduziu o estudo do Direito Romano, tendo composto em 1149 a sua obra Liber ex universo enucleato jure exceptus (46). E pelos meados dêsse século funcionavam, além de outras, umas escolas privadas anexas ao convento agostiniano de Sta. Frideswyde.

Mas o studium generale oxoniense definitivamente se firma a partir de 1167, quando estudantes estrangeiros, entre os quais muitos inglêses, expulsos de Paris, segundo refere João Sarresberiense, vieram constituir em Oxford

(46) Savigny, $I V, 92-3$. 
uma verdadeira população cosmopolita, acrescida pela secessão parisiense de 1229-31. E como em Paris as abadias de SS. Vítor, de Sta. Genoveva e as escolas catedrais de Notre Dame foram os centros onde se agruparam as primeiras escolas, em Oxónia êsse papel desempenhavam as abadias de Sta. Frideswyde e Oseney.

Em 1208-9, em consequência de lutas entre estudantes e a burguesia local, dois dêles foram mortos. Êsse facto provoca uma emigração em massa de cêrca de 3.000 escolares, mestres e alunos, uns para Cambridge, cujo nascimento data daí, outros para Reading, e villam Oxoniae scolis vacuam reliquerunt, narra um cronista.

Tão numeroso êxodo se por um lado põe em grave risco de vida o incipiente studium oxoniense, por outro traz certas vantagens. Para colocar a população universitária ao abrigo de tais ataques por parte da burguesia, uma ordenação de 1214, do legado do Papa, Nicolau, reconhece aos magistri e scolares o direito de greve e de secessão; concede-lhes o privilegium fori, ficando então sob a jurisdição do Bispo de Lincoln, representado pelo Arcediago de Oxford, como cancellarius. Assim, "no caso de ser um estudante prêso por um habitante da cidade, deveria ser imediatamente pôsto em liberdade por ordem do Bispo de Iincoln, do Arcediago ou seu oficial, do Chanceler ou da. quele a quem desse o Bispo essa incumbência" (47). O primeiro Chanceler segundio parece, foi o famoso Roberto Grosseteste (Grossum Caput), em 1221, Bispo de Lincoln, em 1235. Além disso a cidade ficava obrigada a contribuir com uma soma anual para a manutenção dos estudantes pobres.

Em 1232, 38 e 40 novos distúrbios foram a ocasião de novos privilégios, conferidos desta vez por Henrique III em. 1255, aumentando-se consideràvelmente o poder do Chance-

(47) Munim., I. p. 2; Rashdali, III, 37. 
ler, que fica autorizado a encarcerar o leigo que ofendesse gravemente um clérigo (48).

Mas já desde 1254 Inocêncio IV velava pela existência e consolidação da Universidade inglêsa, colocando-a sob a proteção de S. Pedro e sua - sub beati Petri et nostra protectione suscipimus, e confirmando os primeiros estatutos outorgados em 1253. E encarrega os Bispos de Londres e de Oxford de defender as imunidades universitárias contra as absorpções do Rei. Por onde se vê, observa Irsay, que a Universidade de Oxford é uma instituição eclesiástica como a de Paris e Bolonha (49). Ao contrário do que sucedeu em Paris, em Oxford o Chanceler vê a sua autoridade aumentar gradualmente; e começando por ser autoridade independente da Universidade acaba por fazer parte integrante dela. Em 1290 eram da sua alçada, refere Rashdall, "todos os crimes cometidos em Oxford, sempre que fôsse parte um estudante, salvo em processo de homicídio ou de mutilação" (50).

Mas, em 1395 uma bula de Bonifácio IX isenta a Universidade de tôda qurisdição episcopal. Revogada por João XXII em 1411, foi restabelecida por Sixto IV em 1479. O Papa é o defensor supremo do studium generale oxoniense.

Os estudantes oxonienses se agrupam, como em Paris e Bolonha, em duas nationes: os boreales, compreendendo ingleses e escoceses; e os australes, onde se incluíam gaélicos e irlandeses. Cada qual com o seu procurador, que permanecem distintos, apesar de as duas nações se fundirem em 1274.

(48) Munim., II, 776, Rashdall, id., 86: Si laius inferat clerico. gravem vel enormem lesionem statim capiatur, et si magna sit lesio incerceretur in castro Oxonie et ibi detineatur quousque clerico satisfiat, et hoc arbitrio Cancellarii et Universitatis Oxonie, si clericus protervus fuerit; si minor vel levis sit iniuria, incarceretur in villa.

(49) Munim., I, 26 e 28, apud Irsay, pág. 126 n. 2 e 3.

(50) Rashdall, op. cit. III, 94. 
Em 1333 deflagram embates violentos entre boreales e australes. Noutra ocasião gaélicos e ingleses entreatacamse furiosamente. Motins e algazarras chegam a ponto, nas ruas de Oxford, que estudantes desejosos de vida mais tranquila vão viver em Stanford, no condado de Lincoln (51)

Clérigos, clerici são êles, à semelhança de Bolonha e Paris, não tendo êsse vocábulo um sentido estritamente eclesiástico. Todos adstritos ao celibato: casando, o mestre perdia o lugar; o estudante fica privado de receber graus.

Muitos clérigos, porém, o são, no sentido eclesiástico do vocábulo. Em particular, religiosos Dominicanos e Franciscanos sobretudo ilustram, como mestres e alunos, a alma mater oxoniense. Dentre os Franciscanos, estabelecidos em Oxford desde 1224, enumeram-se o inclito Roberto Grossum Caput (Grosseteste), já nomeado, "un des plus remarquables hommes de science de ce temps", na expressão De Wulf; Tomás d'lorque, Adão Marsh (de Marisco), Bartolomeu Anglico, Ricardo Rufo, João Pecham, Arebispo de Cantuária; Rogério Marston, Ricardo de Mediavila (Middleton), o grande Rogério Bacon - o instaurador da scientia experimentalis em pleno séc. XIII, espécie de Alberto Magno franciscano (52) - o imortal Duns Scoto, o doctor subtilis, talvez o maior nome do séc. XIII, depois de Santo Tomás.

Os Dominicanos, já em 1205, estabelecidos em Oxford, também honram a Universidade com Ricardo Fishacre, Roberto Bacon, Roberto Kilwardby, Ricardo de Chapwell, Tomás de Suton e outros menores.

(51) A. C. Delacour de Brisay, L'Université d'Oxford et la vie universitaire en Angleterre, Paris, Fischbacher, 928, pág. 21. Livrinho superficial e mal feito, mas com algumas informações úteis.

(52) De Wulf, II, pág. 271, diz de Rogério Bacon: Pour les sciences en générale, Bacon professe um culte dont on lui a fait justement um titre de gloire: sciences naturelles, mathématiques, perspective, optique, géographique, astronomie, alchimie, philologie, il a pratiqué tout cela mieux qu'aucun autre de ses contemporqins...Les applications qu il a fait de la géometrie à la physique sont supérieures à celles des Arabes... Il fabrique et perfectione des instru- 
Fora dessas ordens, são igualmente ilustres: S. Tomás de Cantelupe, bispo de Hereford, o grande jurista S. Edmundo de Cantuária, S. Ricardo de Wyche, todos cancellari notáveis, que terçavam valentemente armas pela autonomia universitária. Concorreram em grande parte para fazer de Oxford a rival de Paris - Oxonialis universitas aemula Parisiensis, diz um cronista (53).

Essa nobre emulação porém não impediu se reconhecesse a supremacia de Paris. Tomando a Alma Mater Parisiense como modêlo, pela sua melhor organização e melhores mestres, Roberto Grosseteste, Cancelário em 1240, convida os professores de Teologia a seguirem a ordem adoptada em Paris; em 1246 Inocêncio IV faz ao Chanceler idêntica recomendação (54). Mas — ainda influência parisiense - em 1252 os estatutos universitários ordenam que ninguém seja licenciado em Teologia antes de ter obtido do Cancelário o certificado de licenciado em Artes (5).

A reconhecida superioridade de Paris não priva porém os mestres oxonienses da autonomia intelectual. Cedo a orientação filosófico-científica difere da de Paris e se impregna de um colorido próprio, mais positivo e utilitário.

ments d'optique ( .) Les textes qu'il consacre à la méthode expêrimentale, à ses conditions, à ses ressources sont devenues célébres. Incomparàvelmente maior que o seu homônimo do séc. XVI, Bacon de Verulam. Com Rogério aparece pela primeira vez a expressão scientia experimentalis. Cf. Gilson, 'E., La Plhilosophie au moyen âge, Paris, Payot, 1922, II, pág. 59. É com Dúns Scoto, seu compatriota, a maior glória da vetusta Universidade, no séc. XIII.

(53) Apud Irsay, pág. 128, n. 6.

(54) Cf. De Wulf, II, pág. 18.

(55) Munim., I, 25, apud Irsay, 127, n. 6: Statuit Universitas Oxoniensis. . quod nullus in eadem Universitate incipiet in theologia nisi prius retexerit in atribus in aliqua Universitate, et nisi legerit aliquem librum de canone Bibliae vel librum sententiarum vel Historiarum. salva Concellario et Universitati magistrorum potestate gratiam huiusmodi defectum patientibus faciendi, cum viderit expedire. - Cf. Rashdiall, III, 50. 
Basta relembrar a importância que assumem nos sistemas de Roberto Grosseteste e Rogério Bacon a matemática e as ciências experimentais, para se compreender como o espirito prático e utilitário da raça não precisou esperar pela vinda de Francisco Bacon para se manifestar de modo inconfundível, em oposição ao que poderíamos chamar o idealismo teológico parisiense (56).

Muitos clerici, que viriam a ser depois magistri, como êsses que acabamos de nomear, eram desprovidos de recursos para o estudo. Razão por que também em Oxford, os collegia surgiram a obviar êsse inconveniente. Com o tempo foi tal a influência que exerceram, que vieram êles a constituir a Universidade, como já fizemos notar.

O mais antigo, segundo uns, é o de Merton, fundado em Surrey, em 1264, por Walter de Merton, oxoniense, Bispo de Rochester transferido em 1274 para Oxford. Mas outros dão a primazia cronológica ao de Balliol, fundado em 1262 por Devorgilla, viúva de João Balliol. Vieram depois: Universty, fundado pelo arcediago Guilherme de Durham em 1249; Worcester, estabelecido em 1283, que começou por ser uma casa de beneditinos; Oriel, fundado por Eduardo III em 1326; Queen's, em 1340, pelo capelão da rainha Filipa — donde o seu nome - Roberto de Eglesfield; New, em 1379, por Guilherme de Wykeham, bispo de Winchester.

Como em Paris, havia estudantes bursiarii: os de Balliol recebiam 8 dinheiros por semana, correspondentes às bôlsas dos de Paris, que iam de 2 a 8 soldos. Assinn, observa Irsay, "as primeiras rendas da Universidade foram na realidade as de seus membros; estudiantes pobres são os seus primeiros beneficiários; foram os homens e não os imóveis os primeiros a serem pagos" (57). Elevado espírito,

56) De Wulf, sôbre Bacon, II, pág. 271: Homme de science, il recueille et accentue les traditions de Oxford, où, dès les debuts de l'université, la méthode expérimentale et l'interpretation des phenamènes de la nature em termes quantitatifs étaient en honneur.....

(57) Irsay, pág. 158. — Sôbre os collegia, v. Rashdall, III, 169-90. 
que sabia colocar o valor das almas acima do das vigas, traves e cantaria!

Essas três famosas e típicas Universidades põem em relêvo o papel que desempenharam como factor do progresso do espírito na Idade Média. Na ordem filosófica, em especial, o aparecimento delas, sobretudo da de Paris, coincide com a fundação das ordens mendicantes e a tradução das obras de Aristóteles, as três causas preponderantes da grande revolução intelectual operada na Europa do séc. XIII. Mas, no campo filosófico, nem as ordens mendicantes teriam exercido a considerável influência que exerceram, nem a Filosofia aristotélica imprimido nova orientação ao pensamento, se não fôssem êsses poderosos centros de cultura Paris e Oxford.

A Universidade medieval descobriu o segrêdo de utilizar homens e coisas para, no esplend'or do séc. XIII, criar na Europa uma cultura filosófica de tal envergadura, que seria necessário retroceder ao tempo de Sócrates, Platão e Aristóteles para encontrarmos a mesma concentração de pensamento, a mesma profundeza de reflexão e o mesmo confiante otimismo na obra da razão humana.

A prodigiosa emprêsa de cristianizar Aristóteles não lograria levá-la a cabo nem ainda o génio másculo de um Tomás de Aquino, se não se houvesse banhado no ambiente propício da organização universitária.

Como a Cavalaria, o Direito Canónico, o Feudalismo, o estilo Gótico, a Universidade, foco de irradiação da imponente síntese escolástica, é uma das magnas instituições medievais. Para ignorá-lo seria mister a fanática miopia de um Michelet e de seus sequazes, que na idade medieval só enxergam superstição grosseira e ignorância crassa, de mistura com a peste e guerras cruéis, a constituir uma sanguinolenta noite de mil anos. Felizmente porém êsse estado de espírito, nos grandes países civilizados do mundo e de 
intensa cultura - França, Inglaterra, Alemanha, Bélgica, onde superabundam medievalistas ilustres - já não passa de uma penosa recordação, desde mais de cinqüienta anos a esta parte. Só espíritos primários, de rudimentar e deficiente formação, e em países que aind'a vegetam na sombra da incultura, ousariam repetir tão soezes calúnias.

Êsses mesmos espíritos não cansam ainda hoje de buzinar que a Idade Média, em matéria de Filosofia, viveu passivamente à sombra do método de autoridade: ipse dixit, Aristóteles assim o afirma! Mas os olhos se lhes desanuviariam se com boa-fé considerassem apenas os processos formativos do espírito, nas disputationes públicas, em Paris e Oxford para a Filosofia e a Teologia, e em Bolonha para o Direito.

Triunfo do puro raciocínio, como hoje raramente se manifesta. Um Duns Scoto, p. ex., êsse poderoso espírito vigorosamente crítico e independente, que sugeriu a Taine a idéia de Hegel, sustentou em 1304 em Paris a tese da Conceição Imaculada. Teve de responder a cêrca de 200 argumentos. "Sem interrupção, narra Bulaeus, citado por Paulsen (op. cit., pág. 42), ouviu-os tranquilamente; depois, com assombrossa memória, repetiu-os na ordem em que foram formulados e solveu as mais inextrincáveis dificuldades e os mais enredados silogismos, com a mesma facilidade com que Sansão se desprendeu dos laços de Dalila." E são do seu grande émulo do séc. XIII, S. Tomás de Aquino, estas memoráveis palavras: locus ab auctoridate quae fundatur super ratione humana est infirmissimus (Sum. Theol. I. ${ }^{\circ}$, q. I. ${ }^{2}$ a. VIII). Da Summa Theologica, um dos monumentos mais característicos do pensamento medieval, disse Faguet (Hist. de la Litt. Fr., Paris, 1905, I, 106), que "toutes les questions philosophiques... y sont abordées et exposées avec une force de refléxion et une abondance d'idées accesoires qui confond l'esprit."

O que passava em Paris e Oxford com a Filosofia e a Teologia, dava-se em Bolonha com o Direito. A escola dos glossadores, nascida com Irnerio, o célebre mestre bolonhês 
levou ao fastígio o estudo do Direito Romano no séc. XIII, a ponto de Savigny não temer afirmar que é impossível o estudo a fundo de certas questões de direito moderno sem remontar aos escritos dêles (op. cit., IV, 136). O terem. os mestres de Bolonha se alçado a tão elevado nível de cultura jurídica, fàcilmente o compreenderá quem atender ao sistema escolástico da sua argumentação. O professor, historia Savigny (op. cit. IIII, 388), autoridade máxima nêsit:s assuntos, começa propondo a summa ou título a ser explicado no curso; passando em seguida às diferentes leis, lê o têxto adoptado, indica a espécie da lei, resolve as antinomias aparentes, deduz as regras gerais do direito (brocarda) e refere em seguida os processos reais e fictícios cuja decisão se podiam achar nessas leis (quaestiones)."

Compare-se tão forte formação, geratriz do hábito de distinguir e subdistinguir, para bem adaptar à disposição legal o facto concreto, com o sem número de citações que se lêem em qualquer obra moderna de Direito, ou em razões (que de razões só têm o nome. .) de qualquer advogado, mesmo famoso, e se poderá calcular a distância imensa que medeia entre o ensino da Universidade medieval e o das escolas actuais. Se em Direito se pode falar em magisic: dixit, já vê o leitor onde tem êsse lema o seu triunfo!

Por essa intensa formação universitária é que se explica a clareza do espírito francês, tão manifesta na sua língua; pois a França foi por excelência a nação plasmada pela sua incomparável Universidade. Brunetière categòricamente o afirma: "Les définitions de la scholastique n'ont rien de scientifique au sens véritable du mot; mais elles n'en ont pas moins discipliné l'esprit français en lui imposant ce besoin de clarté, de précision et de justesse qui ne laissera pas de contribuer pour sa part à le fortune de notre prose... À coup sur, nous ne pourrons pas ne lui être reconnaissants de nous avoir appris à composer; et là, comme on sait, dans cet équilibre de la compositions dans cette subordination du détail ḋ l'idée de l'ensemble, dans cette juste proportion de 
parties, là sera l'un des attraits, éminents et caracteristiques de la littérature française. Comme si l'on disait qu'en même temps qu'il se manifestait comme un esprit de satire et $d \epsilon$ fronde, l'esprit français se déterminait d'autre part comme un esprit de logique et de clarté." (Manuel de l'Histoire de la Littérature Francaise, Paris, Delagrave, 1919, págs. 24-6). Completando essas idéias, assevera A. Darmsteter no seu belo livrinho, La Vie des Mots Paris, Delagrave, 11e. ed. pág. 72 n. 1): “C'est à la scolastique et au bas latin, disons-le en passant, que le français doit l'incomparable netteté qu'il apporte dans la langue philosophique."

A todos êsses benefícios, dela redundados em nós, acresce que da universidade medieval provieram as universidades modernas. Grandes diferenças porém as separam. As universidades modernas, a partir da Renascença, são criações de príncipes e do Estado, que as absorve cada vez mais. Desaparece assim o princípio fecundo da liberdade do trabalho intelectual, característica dos studia generalia medievais. Cada mestre eminente podia fundar a sua escola e ensinar; da sua capacidade dependia seu êxito. E' assim, que vemos acorrer da Europa inteira estudantes ávidos de ouvir um S. Tomás ou um Duns Scoto, como no séc. XII constituiram multidões os que rodeavam Abelardo na Escola Sta. Genoveva. Para ensinar só há uma condição: ter génio. e saber. E qual não seria a repercussão e a influência de tais escolas, observa Savigny, em tempo em que eram tão poucas e o ensino só se transmitia oralmente! Sem a concorrência dos ginásios e dêsse aluvião de livros, que hoje surgem de todos os lados, as universidades medievais desempenhavam papel muito mais importante que a universidade moderna.

Que nobre orgulho o dos professores, quando de tôda Europa acudiam estudantes cheios de entusiasmo a passar longos anos em Paris e Bolonha para lhes seguir as lições! (op. cit. III, 114-5). 
E quanto mais reflectirmos no papel desempenhado por êsses luminosos focos de intensíssima cultura, mais nos compenetraremos das múltiplas lições, que os modernos nêles poderiam haurir (58).

NOTA. - Este modesto estudo não pretende a nenhuma espécie de originalidade. Nas fontes abaixo enumeradas o leitor encontrará todo o material empregado. Será fácil verificá-lo.

Rashdall, Hastings, The Universities of Europe in the Middle Ages, new edition by F. M. Powicke and A. B. Emden, 3 vols., Oxford, Claredon Press, 1936. No 1.0 vol.: Salerno-Bologne-Paris; no 2. Italy-Spain-France-Germany - Scotland, etc.; no 3..$^{\circ}$ : English Universities-Student life. - Obra imprescindivel para o estudo da matéria.

F. C. de Savigny, Histoire $d u$ droit romain $a_{u}$ moyen âge, tr. Guenoux, Paris, 1839, Hingray, 6 vols.; todo o estudo sôbre a Universidade de Bolonha fomos buscá-lo nessa obra fundamental. Statuta et privilegia almae universitatis Juristarum Gymnasii Bononiensis, ed. de 1561, de que dá longos excertos Savigny, no fim do vol. IV da obra supra citada.

D'Irsay, Stephen, Histoire des Universités, 2 wols., Paris, Picard, 1933-35; obra continuada por René Aigrain num $3 .^{\circ}$ pequeno vol. sôbre Les Universités Catholiques, Picard, 1935.

Janssen, Jean, L'Allemagne à la fin $d u$ moyen âge, trad. E. Paris, 8 vols., Paris, Plon 1902-1911.

Taylor, H. Osborn, The Medieval Mind, London, Macmillan, 1927, 2 vols.

o. Dobiache, Rojdesvenski, Les poésies des Goliardes, Paris, Rieder, 1931.

(58) Boa apreciação em Pace: In the calmer apreciation of modern historians the medieval university was a potent factor for enlightenment and social order...Its aroused enthusiasm for learning, and enforced discipline...Its training sharpened the intelligence, yet sugjected reason to faith.. It Was the centre in which the philosophy and the jurisprudence of antiquity were restored and adapted to new requirements...From it the modern university has inherited the essential elements of corporale teaching, faculty organisation, courses of study, and academic degrees; and the inheritance has been transmitted through the manifold upheavals which submerged the ancient learning and rent Christendom itself asunder. 
Schnürer, Gustave, L'Eglise et la Civilisation au moyen âge, tr. A. Castella, Paris, Payot, 3 vols., 1933-35-38; obra de importância capital esta do eminente professor de Friburgo (Suíssa).

Edward A. Pace, ótimos estudos nos vols. 15 e 2 da esplêndida The Catholic Encyclopedia, New York; sob os titulos Universities $e$ Bologna (pág. 369, 188, 194); foi-nos de ajuda preciosa. Na mesma enciclopédia também haurimos boas informações no estudo de D. O. Hunter, art. Oxford, vol. XI.

E. Lavisse et A. Riambaud, Histoire générale, Paris, Colin, 1893, v. II, c. X por Ch. V. Langlois; nas págs. 552-63 o autor revela completa incompreensão da escolástica.

De Wulf, M., Histoire de la Philosophie Médiévale, Paris, Vrin, 2 vols. 1934-46.

Infelizmente não nos foi possivel consultar directamente as seguintes obras fundamentais: Chartularium Universitatis Parisiensis, de Danifle-Chatelain, Paris, 1889-97; Denifle, Die Universitäten des Mittelalters bis 1400, 1 Bd.; Berlin, 1885.

Obras menos consultadas citam-se no corpo do artigo. 